
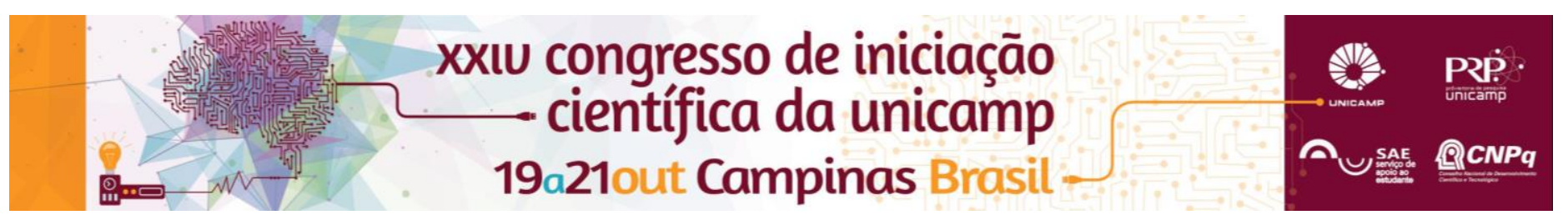

\title{
Produções acadêmicas sobre Jogo e Brincadeira
}

\section{Ana Beatriz Raszl Cortez ${ }^{\star}$ Elaine Prodócimo}

\begin{abstract}
Resumo
O estudo teve como objetivo levantar e analisar as publicações sobre jogo e brincadeira no contexto escolar em revistas nacionais indexadas da área de Educação Física, bem como dissertações e teses produzidas na Faculdade de Educação Física da Universidade Estadual de Campinas - FEF-Unicamp, nos últimos 10 anos . Para tanto, foi realizada pesquisa por meio de levantamento bibliográfico sistemático na base do "periódicos.capes" por meio de palavras chave, títulos e resumos e no Sistema de Bibliotecas da Unicamp para as dissertações e teses.
\end{abstract}

\section{Palavras-chave:}

Jogo, brincadeira, escola, produções acadêmicas.

\section{Introdução}

O jogo possibilita uma condição dialógica, que nos convida a exercitar a nossa capacidade expressiva e intercorporal. Concerne a uma situação em que requisitamos ou somos requisitados pelo outro, ou ainda, na qual encontramos o outro em nós mesmos (ZIMMERMANN; MORGAN, 2011). É nesse contexto que vários pesquisadores passam a atribuir uma importância significativa ao jogo e à brincadeira para 0 desenvolvimento integral da criança dentro e/ou fora da escola.

Diante do exposto, questiona-se como o jogo e a brincadeira vem sendo tratados nos estudos na área da Educação Física, mas especificamente na Educação Física escolar. Realizar um estudo de levantamento bibliográfico sistemático sobre 0 assunto beneficiará os profissionais que atuam com esse conteúdo da cultura corporal em suas práticas pedagógicas, pela facilidade de acesso às informações produzidas, bom como analisar o olhar que vem sendo dado sobre o assunto e quais pontos vem sendo abordados sobre o tema.

\section{Resultados e Discussão}

O levantamento bibliográfico foi realizado abarcando as 19 revistas de melhor indexação na área da Educação Física, nos estratos qualis A1, A2, B1, B2 para o levantamento de artigos e a base de dados acervus da UNICAMP para o levantamento dos TCCs, dissertações e teses. Este levantamento acarretou em um total de 56 trabalhos, que foram analisados quanto às suas estruturas e também quanto ao seu conteúdo.

A análise estrutural permitiu constatar que a maioria dos trabalhos foi publicada entre 2011 e 2014.

Já a análise dos conteúdos permitiu selecionar 12 trabalhos que abrangem a temática do jogo e do brincar na escola, sendo 3 artigos, 3 dissertações e 6 TCCs, nenhuma tese sobre o tema foi encontrada.

Os autores que embasam a conceituação de jogo e brincadeiras foram principalmente Huizinga, Brougere, Piaget e Vigotsky que foi uma referência em destaque, aparecendo como principal fonte de conceitos em 5 dos trabalhos analisados.

$\mathrm{Na}$ análise estrutural, que abrangeu todos os 56 trabalhos encontrados, foi possível constatar que na maioria - aproximadamente $67 \%$ - foi realizada pesquisa de campo.

A leitura completa dos 12 trabalhos que abrangeram o tema proposto permitiu a constatação da prevalência de temas que defendem o uso de jogos cooperativos no ambiente escolar - 3 TCCs $O$ enfoque destes trabalhos ao tratarem dos jogos cooperativos estava em pensar na utilização destes na transformação da sociedade capitalista, por meio de sua proposta na Educação Física escolar.

Houve ainda a recorrência do tema mediação, acerca do papel do professor e da escola na formação do aluno. Mediação que se apresentou em diversos sentidos, mas sempre com o objetivo de proporcionar a ampliação dos benefícios e desenvolvimentos provocados pelo brincar.

\section{Conclusões}

Os dados permitiram a constatação de que mais estudos a respeito do tema precisam ser realizados a fim de ampliar os conhecimentos na área. O jogo e/ou o brincar são conteúdo da cultura corporal do movimento, e, portanto, são de grande competência da área da Educação Física, e um conteúdo tratado não apenas na Educação Física escolar. Foi possível verificar que o tema suscita diferentes possibilidades de abordagens, e o jogo e a brincadeira são tratados, por vezes, de formas distintas, às vezes como fim em si, e outras como meio.

É frequente a referência quanto a sua importância de sua presença no contexto escolar.

Desta forma, novos estudos permitirão o enriquecimento da prática profissional de professores não apenas de Educação Física.

\section{Agradecimentos}

Pesquisa fomentada pela bolsa do PIBICPrograma Institucional de Bolsas de Iniciação Científica. Vigência da bolsa 07/2015- 07/2016.

ZIMMERMANN, A. C.; MORGAN, J. The Possibilities and Consequences of Understanding Play as Dialogue. Sport, Ethics and Philosophy, v. 5, n. 1, p. 46-62, 2011. 